\title{
Improving Filtration Efficacy of Medical Face Masks
}

\section{Aerosol and Air Quality Research}

\author{
Ilpo Kulmala*, Kimmo Heinonen, Satu Salo
}

Technical Research Centre of Finland VTT Ltd., 33720 Tampere, Finland

\begin{abstract}
We built a simple unipolar positive corona charger and tested it with five different medical face masks. Charging the particles significantly enhanced the filtration efficiencies of all of the masks in terms of the submicron fraction, with an average increase of from 58 to $93 \%$ for $0.3 \mu \mathrm{m}$ particles. Simultaneously, the pressure drop remained practically the same, showing the high potential in using electret media. However, the corona discharge generated ozone, which is an issue that must be addressed. These results contribute to the development of effective solutions against airborne threats.
\end{abstract}

Keywords: Medical face mask, Filtration efficiency, Charging, Bioaerosols

\section{INTRODUCTION}

The use of face coverings has been found effective in reducing infection risk via the transmission of respiratory droplets (Rader et al., 2021). Face masks in the community have been recommended as a non-pharmaceutical intervention in combination with other measures as part of efforts to control the COVID-19 pandemic (ECDC, 2021). Research has shown that higher-grade respiratory masks (e.g., N95 respirator) were associated with lower infection risk compared to surgical and home-made cloth masks (Li et al., 2021). As the concerns of airborne transmission of SARS-CoV-2 increase, the respiratory protection of general public and health care personne becomes more important (Samet et al., 2021).

There are various national and international standards for testing and certifying particulate respirators (Rengasamy et al., 2017). The test methods for measuring filtration efficiency in these standards vary by the type of aerosol, particle size distribution and flow rate through the respirator. In the USA, the National Institute for Occupational Safety and Health (NIOSH) tests and certifies 95, 99, and 100 Series particulate filters and respirators, with minimum required filtration efficiencies of 95\%, 99\%, and $99.97 \%$ for $0.3 \mu \mathrm{m}$ particles, respectively (Federal Register, 1995). In the European Community, the minimum efficiencies for FFP2 and FFP3 filtering facepiece respirators are $94 \%$ and $99 \%$ against paraffin oil according to EN-149 (CEN, 2009). For the medical face masks, the filtration efficiency is determined by using bioaerosol and impactor samplers. The medical face masks are classified into Type I and II based on the bacterial filtration efficiency (BFE) in the size range of $0.65-7 \mu \mathrm{m}$ (CEN, 2019). For Type I masks the BFE should be at least $95 \%$ while for Type II masks it should be $>98 \%$.

Disposable medical face masks have typically three different layers of nonwoven fabric with each layer having a specific function. The outermost layer is spunbond and helps repel fluids like mucosalivary droplets. The middle layer is most commonly made of polypropylene which is meltblown to obtain fibers with small diameter in a random orientation. The fibers are electrically charged during the manufacturing process to have electret properties to enhance the collection efficiency of fine aerosols. The innermost layer is made of absorbent materials to trap mucosalivary droplets from the user. This layer also absorbs the moisture from exhaled air, thus improving comfort (Chua et al., 2020). These three layers are assembled through ultrasonic welding.

The medical face masks may not protect the wearer well from airborne particles due to the only moderate filtration efficiency in the submicron size range and also because of leakages of air around the masks' edges (Oberg and Brosseau, 2008; Grinshpun et al., 2009; Rengasamy et 
al., 2014). However, it is possible to enhance the performance of face masks by utilizing strong electrical forces to trap submicron particles. Lee et al. (2004a) enhanced the filtration efficiency of medical face masks and N95 respirators with the aid of a powerful negative ion emitter in a 24 $\mathrm{m}^{3}$ test chamber. Their studies showed that the particle penetration of N95 respirator and surgical face mask decreased drastically due to the emitted ions increasing the charge of airborne aerosols. However, this may be an impractical control strategy for airborne pathogens. Firstly, at the same time, the deposition rate of particles on surfaces of the test chamber increased over 20-fold for aerosols in the size range of 0.04-2 $\mu \mathrm{m}$ (Lee et al., 2004b). In case there are bioaerosols in the air, they may deposit on surfaces causing contact hazard. Other studies have shown that for example SARS-CoV-2 viruses can survive on different surfaces for days (van Doremalen et al., 2020). Secondly, it is not known how well the ion emitter will work for greater distances than the $20 \mathrm{~cm}$ used in the tests between the emitter and dummy head wearing face mask, or in larger spaces. Thirdly, powerful negative ion generators may produce excessive concentrations of harmful by-products like ozone and nitrogen oxide (Lee et al., 2004b).

The aim of this study was to demonstrate how the filtration efficiency of normal medical face masks can be improved with a simple battery-operated charger made from widely available materials. The charging of particles has been successfully employed for improving the performance of air filters used in general ventilation of buildings (Huang et al., 2008; Kulmala et al., 2020) but so far its use in personal protection has not been reported.

\section{METHODS}

To facilitate electrical enhancement, the particles in the air entering the mask needs to be charged. This was realized by constructing a simple unipolar needle charger for diffusion and field charging. The discharge electrode was made of a short piece of tungsten wire (diameter $=0.3 \mathrm{~mm}$, length $=10 \mathrm{~mm}$ ) located co-axially in a grounded aluminium tube (inner diameter $=36 \mathrm{~mm}$ ). The positive corona discharge was created at the tip of the thin tungsten wire by applying high voltage $(+6.6 \mathrm{kV})$ to the electrode. The length of the tungsten wire then acted as a non-discharging electrode providing also a non-uniform electric field in the ionizing section. The charger was attached to a plastic holder as shown in Fig. 1. The weight of the plastic holder and charger was $75 \mathrm{~g}$.

To demonstrate how the device can be made of widely available low-cost materials, the highvoltage power supply was made from two battery-operated electric mosquito racket zappers

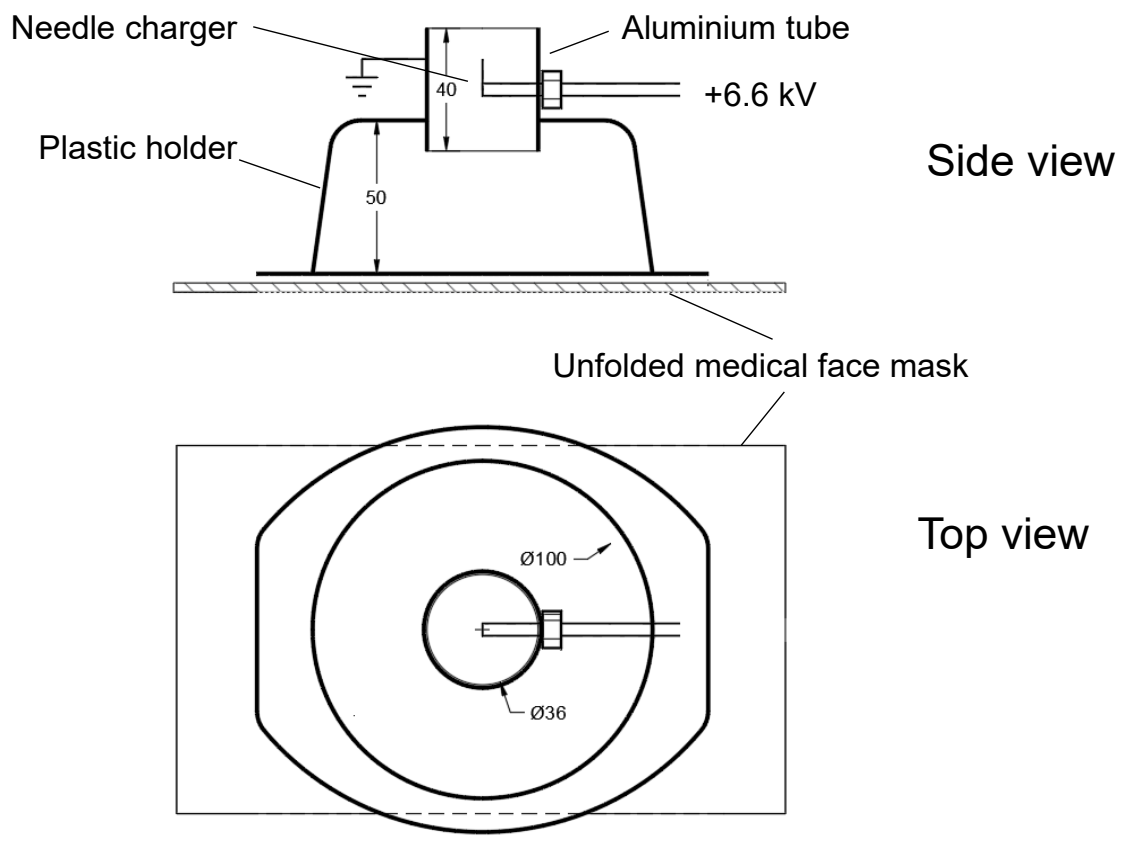

Fig. 1. Construction and size of particle charger. Dimensions in $\mathrm{mm}$. 


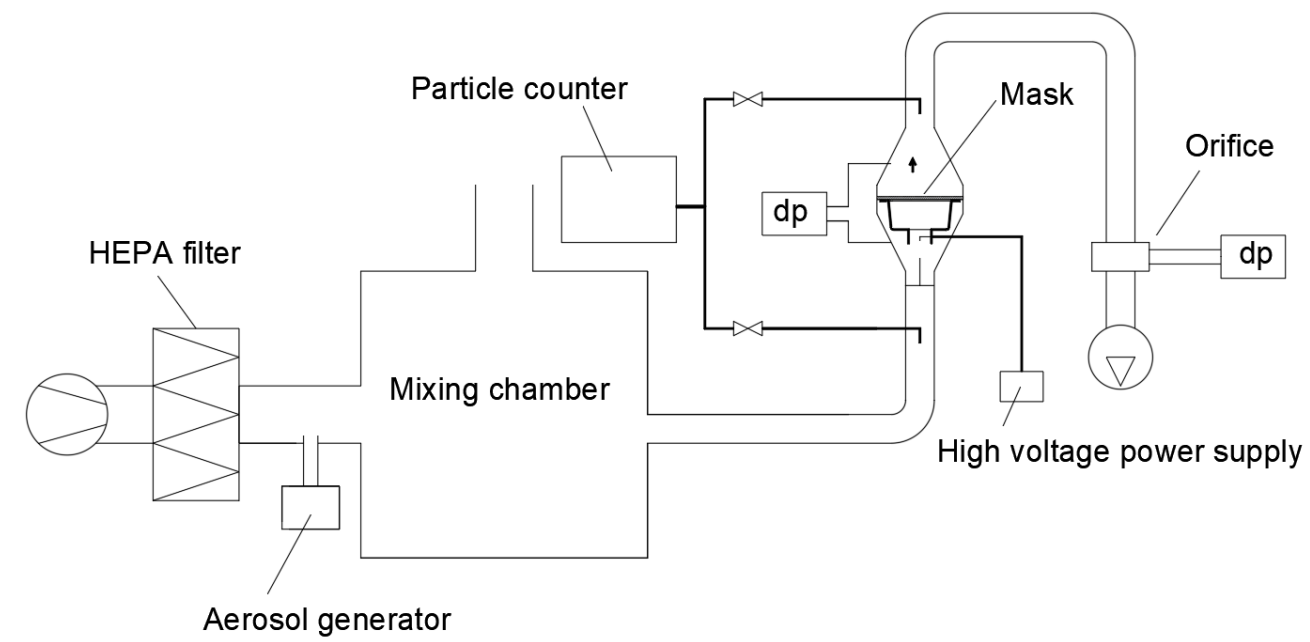

Fig. 2. Test system for filtration efficiency and pressure drop measurements.

connected in series to give a voltage of $6.6 \mathrm{kV}$. With this voltage the measured charger current was $10 \mu \mathrm{A}$. This current was applied during the whole filtration efficiency measurement cycle.

In the electrically enhanced filter the airborne particles were first drawn into charger and then passed through the medical face mask filter media. The medical face mask which has typically dimensions of $175 \times 95 \mathrm{~mm}$ was unfolded and placed downstream the holder between two thin annular plates. The inner diameter of the annular plate was $100 \mathrm{~mm}$ with an open area of $79 \mathrm{~cm}^{2}$. The airflow rate used in the tests was $95 \mathrm{~L} \mathrm{~min}^{-1}$ corresponding to filter media velocity of $0.20 \mathrm{~m} \mathrm{~s}^{-1}$.

The filtration efficiency of the face mask material was measured with a test system shown in Fig. 2. The system consists of aerosol generator, mixing chamber, sample lines, sample holder and measurement of particles. The aerosol generator was a container with diethylhexyl sebacate (DEHS) liquid and a Laskin nozzle. The DEHS aerosol was generated by feeding compressed particle-free air through the nozzle and the atomized droplets were then introduced into mixing chamber from which air was led to the mask to be tested.

The particle concentrations were measured in turn upstream and downstream of the filter material with an optical particle counter (LAS-X II; Particle Measuring Systems, Boulder, CO). The size-dependent filtration efficiency was determined from the measured concentrations as:

$E(d)=\left[1-C_{2}(d) / C_{1}(d)\right] \cdot 100(\%)$

where $C_{1}(d)$ is the particle concentration upstream and $C_{2}(d)$ downstream the filter. From the results the average filtration efficiency and $95 \%$ confidence limits were calculated.

The flow rate through the mask material was measured with a standard orifice. The airflow used in the tests $\left(95 \mathrm{~L} \mathrm{~min}^{-1}\right.$ ) is equal to that used in the standard EN 149 for testing FFP2/FFP3 respirators. The flow rate was thus significantly higher than in the medical face mask tests (28 L min $\mathrm{m}^{-1}$ as specified in EN 14683). The pressure drop over the filter material was measured with a micromanometer. In total, five different masks were measured of which one was of Type I and four Type II.

To determine the ozone generation rate of the charger, ozone concentration was measured downstream the charger holder with an ozone analyzer (Model 0341; Environnement S.A., Poissy, France). The supply air to the test system was filtered with an activated carbon filter to remove background concentration.

\section{RESULTS AND DISCUSSION}

An example of the measured filtration efficiencies without and with charger is shown for Type I and II masks in Fig. 3. These present the lowest and highest filtration efficiencies among the tested face masks. A summary of the performance of the mask materials is presented in Table 1. 
Type I Medical face mask dp=94 Pa @ 95 Ipm

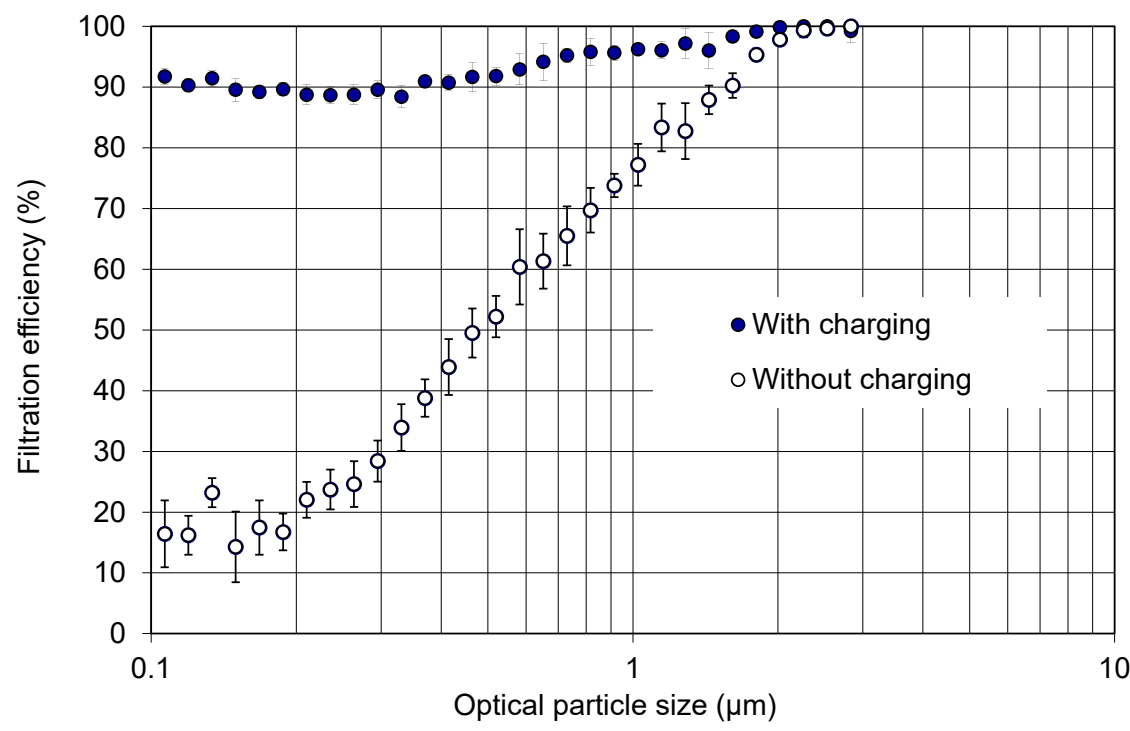

Type II Medical face mask dp=140 Pa @ 95 Ipm

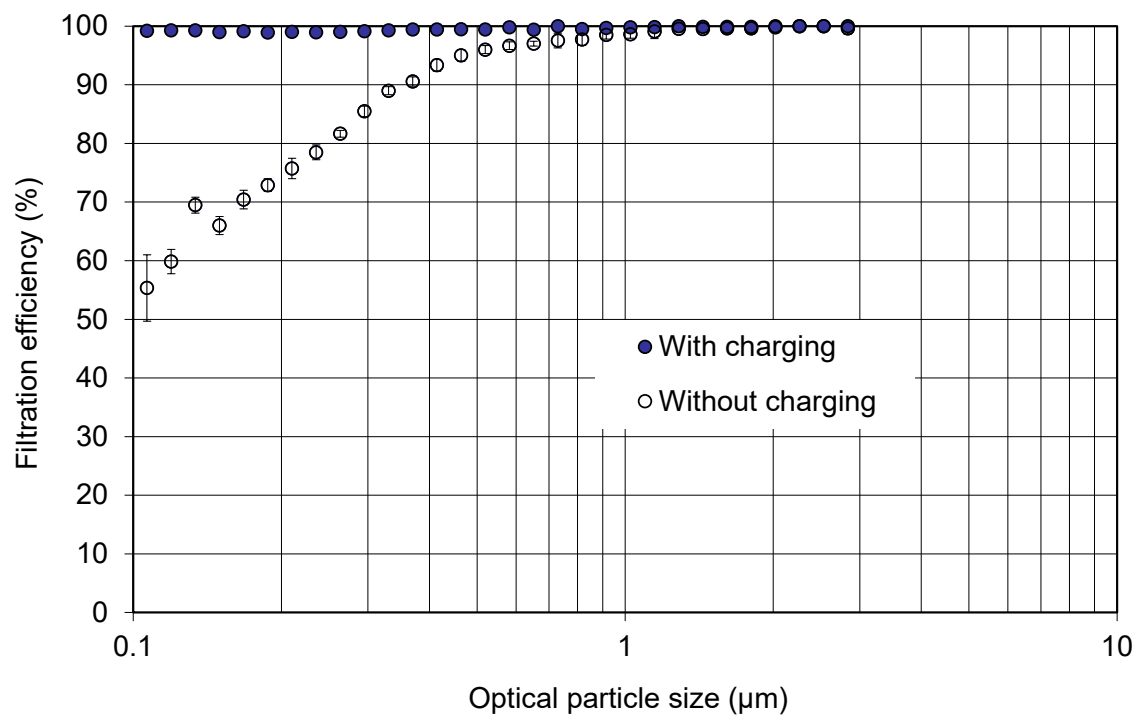

Fig. 3. Filtration efficiencies of type I and II face masks in normal condition and with particle charging.

Table 1. Summary of the measured face masks measured at $95 \mathrm{~L} \mathrm{~min}^{-1}$.

\begin{tabular}{lllll}
\hline \multirow{2}{*}{ Mask \# } & \multirow{2}{*}{ Class } & Pressure drop & \multicolumn{2}{c}{ Filtration efficiency @0.3 $\mu \mathrm{m}(\%)$} \\
\cline { 4 - 5 } & & $(\mathrm{Pa})$ & without charging & with charging \\
\hline 1 & Type I & 94 & 28.4 & 89.6 \\
2 & Type II & 133 & 70.6 & 96.6 \\
3 & Type II & 99 & 49.0 & 92.5 \\
4 & Type II & 140 & 85.5 & 99.2 \\
5 & Type II & 135 & 53.9 & 89.2 \\
Average & & 120 & 57.5 & 93.4 \\
\hline
\end{tabular}

The particle charging improved the medical masks' filtration efficiency significantly. Without charging both the Type I and Type II surgical face mask materials had only moderate removal efficiency against fine particles: For Type I mask materials the efficiency was only about $20 \%$ and 
for Type II about $55 \%$ for $0.1 \mu \mathrm{m}$ particles. The efficiency increased with particle size as can be seen in Fig. 3. Charging of particles even at currents as low as the used $10 \mu \mathrm{A}$, the efficiency increased to near or over FFP2 level (>94\%). With one mask (\#4) having relatively high initial efficiency, the improvement was up to FFP3 level (99\%). The corresponding electric power consumption of the charger was only $70 \mathrm{~mW}$ meaning that the high-voltage supply could well be battery-operated continuously several hours or even days.

A major challenge with air filtration is to achieve high removal efficiency with acceptable pressure drop. Charging the particles offers great potential because the filtration efficiency can be significantly improved without increasing pressure losses. The flow resistance of the charger itself was low, $2.5 \mathrm{~Pa}$ at $95 \mathrm{~L} \mathrm{~min}^{-1}$, compared to the pressure drop over the filter media.

The solution has important advantages. Most importantly, the widely available and relatively low-cost surgical face masks with electret filter media can be enhanced so that the filtration efficiency reaches that of FFP2 or FFP3 respirators. The pressure drop of the solution is also low, in the example from 94 to $135 \mathrm{~Pa}$ with an air flow of $95 \mathrm{~L} \mathrm{~min}^{-1}$, while according to EN 149 it can be up to $240 \mathrm{~Pa}$ with FFP2 respirators and $300 \mathrm{~Pa}$ with FFP3 respirators. Thanks to the low pressure drop, the breathing resistance is low, so the solution does not burden the user like FFP2 masks. However, the improvement will last only so long as the charger is operating so that discontinuation of the charging of inflowing particles will cause the efficiency to drop to its initial level.

In previous studies it has been shown that respiratory protection provided by a particulate respirator is a function of particle penetration through filter media and through face seal leakage. In practical applications, the face seal leakage needs to be addressed because this is the major leak path with surgical face masks with low filter media penetration (Grinspunh et al., 2009; Rengasamy et al., 2014).

The viral particles emitted during coughing and sneezing by a person with respiratory infection are mainly in large droplets (Nicas et al., 2005). For such large particles the removal efficiency of surgical face mask filter material is high even without any electrical enhancements. On the other hand, recent study by Alsved et al. (2020) show that singing and even talking generates many particles in the submicron size range. The number of viruses in these fine aerosols depend on the viral load in the respiratory fluids and may be large enough to cause airborne hazard if the concentration of infective viruses is very high (Anand and Mayya, 2020). For such cases the enhanced filtration can provide additional protection.

Corona discharge creates ozone which can cause adverse health effects at elevated concentration levels. The measured ozone concentration downstream the charger was $94 \mu \mathrm{g} \mathrm{m}^{-3}$ when using the same charger current and voltage as in the filtration efficiency measurements. This is slightly below the World Health Organization (WHO) guideline value of $100 \mu \mathrm{g} \mathrm{m}^{-3}$ as an 8-hour mean for air quality (WHO, 2006). The NIOSH occupational exposure value for ozone is $200 \mu \mathrm{g} \mathrm{m}^{-3}$ (NIOSH, 2007). These figures suggest that ozone generation may be an issue which needs to be addressed if corona charging is utilized in personal protection applications.

This study concentrated on the improvement of the efficiency of the respirator media. It shows that there are great opportunities in protection of people by fully exploiting the potential of electret materials. As awareness of airborne threats is growing and an increasing number of countries require citizens to wear masks in public places, a demand for high-efficiency masks will increase. One sustainable and affordable solution could be reusable and cleanable filter holder with miniature high-voltage power supply for charger combined with disposable medical masks or other suitable electret materials. However, further development and other innovative solutions are needed to ensure leak-free construction of such a respirator protector.

\section{CONCLUSIONS}

Charging the particles with a positive unipolar corona charger markedly increased the filtration efficiencies of five different medical face masks in terms of the submicron fraction, with the highest-quality mask achieving the FFP3 standard. This modification requires only a very lowpower charger and does not significantly raise the filter pressure drop, demonstrating large potential for practical applications. However, further research is needed to minimize the health risks from the generated ozone and ensure the safety of the user. 


\section{ACKNOWLEDGMENTS}

Business Finland funded this study in the MaskKill project. Mr. Hannu Nieminen is thanked for manufacturing the charger.

\section{REFERENCES}

Alsved, M., Matamis, A., Bohlin, R., Richter, M., Bengtsson, P.E., Fraenkel, C.J., Medstrand, P., Löndahl, J. (2020). Exhaled respiratory particles during singing and talking. Aerosol Sci. Technol. 54, 1245-1248. https://doi.org/10.1080/02786826.2020.1812502

Anand, S., Mayya, Y. (2020). Size distribution of virus laden droplets from expiratory ejecta of infected subjects. Sci. Rep. 10, 21174. https://doi.org/10.1038/s41598-020-78110-x

Brosseau, L.M., Evans, J.L., Ellenbecker, M.J., Feldstein, M.L. (1989). Collection efficiency of respirator filters challenged with monodisperse latex aerosols. Am. Ind. Hyg. Assoc. J. 50, 544549. https://doi.org/10.1080/15298668991375137

Chua, M.H., Cheng, W., Goh, S.S., Kong, J., Li, B., Lim, J.Y.C., Mao, L., Wang, S., Xue, K., Yang, L., Ye, E., Zhang, K., Cheong, W.C.D., Tan, Beng Hoon, Li, Z., Tan, Ban Hock, Loh, X.J. (2020). Face masks in the new COVID-19 normal: Materials, testing, and perspectives. Research 2020, 7286735. https://doi.org/10.34133/2020/7286735

European Centre for Disease Prevention and Control (ECDC) (2021). Using face masks in the community: first update - Effectiveness in reducing transmission of COVID-19. https://www.ecdc.europa.eu/en/publications-data/using-face-masks-community-reducingcovid-19-transmission (accessed February 23 2021).

European Committee for Standardization (CEN) (2009). EN 149:2001+A1:2009: Respiratory protective devices. Filtering half masks to protect against particles. Requirements, testing, marking. May 2009.

European Committee for Standardization (CEN) (2019). EN 14683: Medical face masks requirements and test methods. August 2019.

Federal Register: 42. (1995). Code of Federal Regulations Part 84. Respiratory Protective Devices. Final Rules and Notice. U.S. Government Printing Office, Washington, D.C., Office of Federal Register, 60, 30335-30398.

Grinshpun, S., Haruta, H., Eninger, R., Reponen, T., McKay, R., Lee, S.A. (2009). Performance of an N95 filtering facepiece particulate respirator and a surgical mask during human breathing: Two pathways for particle penetration. J. Occup. Environ. Hyg. 6, 593-603. https://doi.org/10. 1080/15459620903120086

Huang, R., Agranovski, I., Pyankov, O., Grinshpun, S. (2008). Removal of viable bioaerosol particles with a low-efficiency HVAC filter enhanced by continuous emission of unipolar air ions. Indoor Air 18, 106-112. https://doi.org/10.1111/j.1600-0668.2007.00512.x

Lee, B.U., Yermakov, M., Grinshpun, S.A. (2004a). Unipolar ion emission enhances respiratory protection against fine and ultrafine particles. J. Aerosol Sci. 35, 1359-1368. https://doi.org/1 0.1016/j.jaerosci.2004.05.006

Lee, B.U., Yermakov, M., Grinshpun, S.A. (2004b). Removal of fine and ultrafine particles from indoor air environments by the unipolar ion emission. Atmos. Environ. 38, 4815-4823. https://doi.org/10.1016/j.atmosenv.2004.06.010

Li, L., Niu, M., Zhu, Y. (2021). Assessing the effectiveness of using various face coverings to mitigate the transport of airborne particles produced by coughing indoors. Aerosol Sci. Technol. 55, 332-339. https://doi.org/10.1080/02786826.2020.1846679

National Institute for Occupational Safety and Health (NIOSH) (2007). NIOSH pocket guide to chemical hazards. Department of health and human services. Centers for Disease Control and Prevention. National Institute for Occupational Safety and Health. September 2007. DHHS (NIOSH) Publication No. 2005-149

Nicas, M., Nazaroff, W., Hubbard, A. (2005). Toward understanding the risk of secondary airborne infection: Emission of respirable pathogens. J. Occup. Environ. Hyg. 2, 143-154. https://doi.org/ 10.1080/15459620590918466

Oberg, T., Brosseau, L. (2008). Surgical mask filter and fit performance. Am. J. Infect. Control. 36, 
276-282. https://doi.org/10.1016/j.ajic.2007.07.008

Rader, B., White, L., Burns, M., Chen, J., Brilliant, J., Cohen, J., Shaman, J., Brilliant, L., Kraemer, M. (2021). Mask-wearing and control of SARS-CoV-2 transmission in the USA: A cross-sectional study. Lancet Digital Health 3, e148-e157. https://doi.org/10.1016/S2589-7500(20)30293-4

Rengasamy, S., Shaffer, R., Williams, B., Smit, S. (2017). A comparison of facemask and respirator filtration test methods. J. Occup. Environ. Hyg. 14, 92-103. https://doi.org/10.1080/15459624. 2016.1225157

Samet, J., Prather, K., Benjamin, G., Lakdawala, S., Lowe, J.M., Reingold, A., Volckens, J., Marr, L. (2021). Airborne transmission of Severe Acute Respiratory Syndrome Coronavirus 2 (SARSCoV-2): What we know. Clin. Infect. Dis. ciab039. https://doi.org/10.1093/cid/ciab039

van Doremalen, N., Bushmaker, T., Morris, D.H., Holbrook, M.G., Gamble, A., Williamson, B.N., Tamin, A., Harcourt, J.L., Thornburg, N.J., Gerber, S.I., Lloyd-Smith, J.O., de Wit, E., Munster, V.J. (2020). Aerosol and surface stability of SARS-CoV-2 as compared with SARS-CoV-1. N. Engl. J. Med. 382, 1564-1567. https://doi.org/10.1056/NEJMc2004973

World Health Organization (WHO) (2006). Air quality guidelines for particulate matter, ozone, nitrogen dioxide and sulfur dioxide. Global update 2005. Summary of risk assessment. 